\title{
Saber e ignorância em Aristóteles Um exercício a partir de $A P O$. I 16-18
}

António Pedro Mesquita

No interior do primeiro livro dos Segundos Analiticos, os capítulos 16-18 constituem um excurso inesperado.

Com efeito, sem qualquer solução de continuidade com o que antecede ou com o que sucede', encontra-se aí uma discussão acerca do erro e da ignorância, que nada faria aparentemente prever ${ }^{2}$.

Estes três capítulos estão estreitamente interligados, mas a reconstituição da sua estrutura levanta diversas dificuldades que só podem ser resolvidas por uma consideração atenta do enunciado programático inicial.

Vejamo-lo pois.

A iniciar a sua análise, diz Aristóteles ${ }^{3}$ :

"A ignorância - aquela que é assim chamada não por negação, mas por disp̧osição - é um erro que se gera por silogismo. Este, no caso daquilo que pertence ou não pertence de modo primitivo, acontece de dois modos: ora quando se concebe simplesmente que pertence ou não pertence; ora quando é através de um silogismo que se chega a essa concepção. No caso da concepção simples, o erro é simples; mas no caso da que provém por silogismo, [os erros são] vários"4.

Do ponto de vista que aquui nos interessa, a relação entre saber e ignorância em Aristóteles, o texto divide-se claramente em dois momentos fundamentais. No primeiro, Aristóteles distingue aquilo a que poderíamos chamar a "ignorância negativa" da "ignorância disposicional"s. No segundo, procede à determinação e à exposição das variantes da "ignorância disposicional".

Vale a pena considerá-los separadamente, para podermos depois enveredar pelo ponto fundamental, que é o que diz respeito ao sentido da "ignorância negativa", aqui apenas aludida.

Inteiramente dominado pela análise da demonstração e da ciência demonstrativa em geral.

2 Com efeito, o único paralelo no texto virá a ser um segundo excurso, este final, dedicad• à consideração de dois modos de conhecimento não demonstrativos (capitulos 33-34). Nele se integra, sugestivamente, o importante desenvolvimento sobre a opiniẫo, a que daremos atenção em próxima publicação.

3 APo. I 16, 79b23-29.

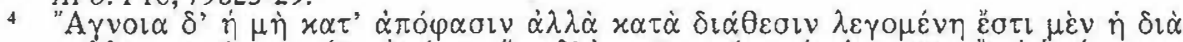

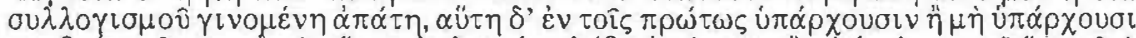

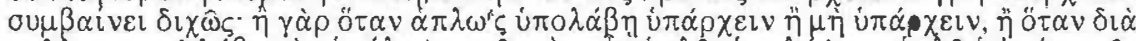

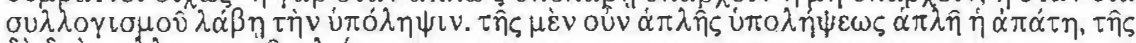

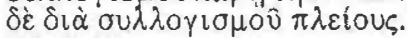

$579 \mathrm{~b} 23-24$.

6 79a23-29. 
O texto começa pois por uma distinção entre dois tipos de ignorância ( $\alpha$ $\gamma v o \imath \alpha)$ : a ignorância por negação ( $\left(\alpha \alpha \tau^{\prime} \dot{\alpha} \pi\right.$ ó $\left.\alpha \sigma \imath v\right)$ e a ignorância por disposição ( $\varkappa \alpha \tau \dot{\alpha}$ $\delta \iota \alpha \dot{\theta} \theta \sigma \iota v)$.

A distinção parece corresponder ao seguinte: no primeiro caso, o ignorante não sabe determinado facto, porque não tem qualquer tipo de convicção sobre ele. No segundo caso, o ignorante não sabe, porque tem uma convicção falsa acerca desse mesmo facto.

Nesta medida, o primeiro tipo diz-se por negação, porque se consubstancia numa pura e simples negação do saber: o ignorante não possui qualquer convicção acerca do facto em causa. O segundo tipo diz-se por disposição, porque se consubstancia numa disposição oposta ao saber: o ignorante tem uma convicção acerca de determinado facto, mas essa convicção é falsa; trata-se, portanto, da ignorância em que consiste propriamente o erro e a disposição em que o ignorante se encontra chama-se engano

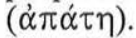

Os dois tipos de ignorância, por negação e por disposição, opõem-se assim duplamente: por um lado, o primeiro é negação (de qualquer convicção) e o segundo é afirmação (de uma conviç̧ão falsa); por outro lado, este gera uma determinada disposição (o erro ou engano), enquanto aquele não gera qualquer disposição (é pura privação de saber).

A esta luz, a ignorância por negação é na verdade uma dupla negação: do saber e de qualquer disposição em relação ao saber; e a ignorância por disposição é na verdade uma dupla disposição: em relação ao saber e enquanto atitude positiva em geral.

Ora, segundo Aristóteles, o que caracteriza a ignorância do segundo tipo (ignorância disposicional ou erro) é que esta resulta sempre de uma inferência (סi⿳亠㐅 $\sigma \cup \lambda \lambda \circ \gamma \imath \sigma \mu \circ \cup$ ). Tal inferência pode assumir todavia duas formas: ou é uma inferência cuja conclusão é oposta de uma proposição imediata ${ }^{7}$ ou é uma inferência cuja conclusão é oposta de uma proposição não-imediata ${ }^{8}$.E, em ambos os $\operatorname{casos}^{9}$, a conclusão falsa pode ser simplesmente postulada, sem construir a inferência correspondente, constituindo portanto apenas como que uma conviçção ou concepção simples $(\dot{\alpha} \pi \lambda \hat{\omega} \varsigma)$, ou pode ser feita derivar de uma inferência efectiva ${ }^{10}$.

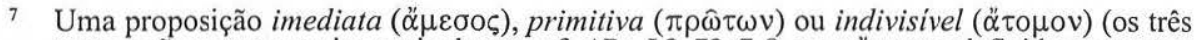
termos são a este respeito equivalentes: cf. $A P o$. I 2, 72a7-8, para $\alpha \mu \varepsilon \sigma o \zeta$ definido em termos

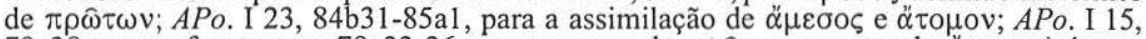

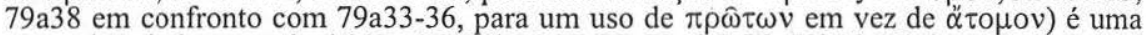
proposição indemonstrável (APo. I 2, 71b26-27; I 2, 72a6-7; I 3, 72b18-25), isto é, inderivável de uma proposição anterior ( $A P O$. I 2, 72a7-8) em que residisse o termo médio por causa do qual ela seria o caso (APo. I 15, 79a33-36). O facto de não ser derivável de uma proposição anterior faz dela uma premissa primitiva (cf. APo. I 2, 71 b26-27, 72a6-7) e, num certo sentido do termo, uma premissa imediata, a saber, enquanto não existe nenhuma outra que lhe seja anterior (cf. $A P O$. I 2, 72a7-8); e o facto de não admitir nenhum termo médio faz dela, literalmente, uma premissa imediata (isto é, "sem meio": $\dot{\alpha}-\mu \varepsilon ́ \sigma o \zeta)$ e, nesta acepção, uma premissa indivisivel, a saber, justamente porque lhe falta um meio por onde pudesse ser dividida (cf. APo. I 15, 79a33-36).

8 O segundo membro da alternativa não surge expressamente no enunciado programático, mas

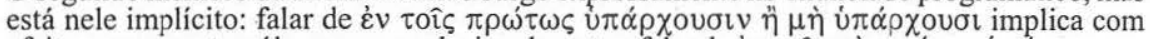

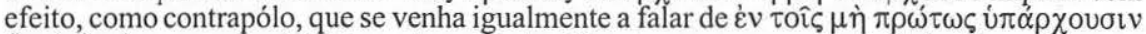

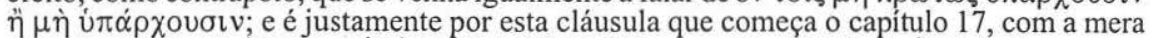

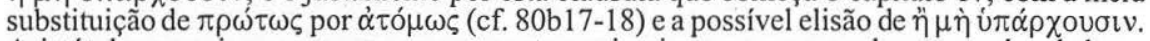

9 Aristóteles menciona apenas expressamente o primeiro caso e em nenhum outro local alarga expressamente a lição ao segundo: mas é evidente que o que se diz da inferência de conclusões opostas a proposições imediatas é, a este respeitọ, válido também para a inferência de conclusões opostas a proposições não-imediatas. E também esta perspectiva que BARNES consagra no esquema com que inicia o seu comentário ao presente capítulo (cf. Aristotle's Posterior Analytics, Oxford, Clarendon Press, $1994^{2}$, p. 164).

10 Ross entende que Aristóteles comete aqui uma contradição: "He first (79b24) identifies the latter [ $\alpha \ddot{\gamma} v \circ \iota \alpha$ as a positive state] with wrong opinion reached by reasoning, but later (b25- 
No caso da conclusão simples, o erro assume apenas uma única forma: porque se trata sempre de postular a conclusão oposta à proposição verdadeira e, para cada proposição verdadeira, há uma única proposição oposta, a saber, a sua negação ${ }^{11}$. Mas no caso em que a inferência é efectivamente construída, esta pode assumir uma variedade de formas silogísticas e, portanto, o erro pode ser produzido de diferentes modos.

É precisamente a apresentação das condições sob as quais o erro pode ocorrer na inferência de uma conclusão oposta a uma proposição imediata ou na inferência de uma conclusão oposta a uma proposição não-imediata e das diversas formas silogísticas que em cada caso podem assumir essas inferências que constitui respectivamente o tema do capítulo 16 e do capítulo 17 . O capítulo 18 , por seu lado, será dedicado à apresentação da natureza e origem da ignorância negativa.

Com efeito, após ter examinado o primeiro e o segundo tipos de ignorância disposicional (ou erro), respectivamente resultantes da inferência da conclusão oposta a uma proposição imediata ${ }^{12}$ e da inferência da conclusão oposta a uma proposição mediata ${ }^{13}$, Aristóteles entrega-se neste último capítulo à análise da ignorância negativa (ou ignorância estrita), isto é, daquela que repousa sobre uma privação sensorial.

$\mathrm{O}$ texto segue assim ${ }^{14}$ :

"É evidente que se falta um sentido, necessariamente faltará também a ciência correspondente. E é então impossivel atingi-la, visto que aprendemos ou por indução ou por demonśtração; ora, a demonstração procede a partir de universais e a indução a partir de particulares, mas é impossivel apreender os universais senão através da indução (pois mesmo as noções constituídas por abstracção são tornadas mais claras pela indução, a saber ${ }^{15}$, as coisas, ainda que não separadas, que pertencem a cada género em virtude de este ser de tal ou tal modo) ${ }^{16}$ e é impossivel induzir sem possuir sensação. Com efeito, a

-28) corrects himself by dividing it into wrong opinion so reached and that formed without reasoning". (Aristotle's Prior and Posterior Analytics. A Revised Text with Introduction and Commentary, Oxford, Clarendon Press, 1949, p. 559) Mas a verdade é que não é necessário atribuir-lhe semelhante reviravolta (a apenas duas linhas de distância!), se considerarmos, como o fazemos aqui, que Aristóteles não está a sugerir que neste caso o erro se produz sem inferência, mas apenas que ele se produz sem que a inferência seja efectiva ou expressamente construida. De outro modo ter-se-ia de abdicar do carácter inferencial como traço diferenciador da ignorância $x \alpha \tau \dot{\alpha} \delta \imath \alpha \dot{\theta} \varepsilon \sigma \iota \nu$, e portanto como traço diferenciador do erro, quando esta constitui a tese axial de Aristóteles neste ponto: todo o erro é resultado de uma inferência, mesmo quando, como é aqui o caso, essa inferência não é efectivamente construída (porque a conclusão é tomada de outrem) ou não é expressamente construída (porque não se tem consciência de a ter construído, passando, por consideração atemática das premissas, directamente à conclusão).

1 E por esse motivo não volta Aristóteles a falar nesta variante que, verdadeiramente, só mencionou por escrúpulo de exaustão.

APo. I 16, 79b29-80b16.

13 APo. I 17, 80b17-81a37.

14 APo. I 18,81a38-b9. O carácter extremamente elíptico do texto e a pontuação difícil da edição obrigam-nos a parafrasear mais do que o costume nesta tradução.

15 Para o valor de ő $\tau$ neste passo veja-se RolfEs, Organon, IV, Leipzig, F. Meiner, 1918-1922 (reedição: Aristoteles. Philosophische Schriften, I-II, Darmstadt, Wissenschaftliche Buchgesellschaft, 1995) e Barnes, op. cit., bem como MignuCCI, L'argomentazione dimonstrativa in Aristotele. Commento agli Analitici Secondi, I, Padova, Antenore, 1975, nn. ad loc. No mesmo sentido, cf. Verdenius, "Notes on Some Passages from Book I", Aristotle on Science: the Posterior Analytics. Proceedings of the Eighth Symposium Aristotelicum, ed. E. Berti, Padova, Antenore, 1981, p. 350.

16 Observa com justeza BARNES que "Even if the defence succeeds, its conclusion is not strong enough; for it argues only that induction can make abstactions familiar, when Aristotle needs to argue that abstractions can only be made familiar by induction. An $\Gamma$ 8, 432a3-6, offers a different and stronger argument for the the view that 'objects of comprehension, both what 
sensação é dos casos individuais. E, neste caso, não é possível atingir a ciência [a partir] deles: pois [não é possível fazê-lo] nem através dos universais sem indução, nem através da indução sem sensação"17.

A tese a demonstrar é manifestamente que toda a privação de conhecimento (isto é, nos termos de $A P o$. I 16, toda a ignorância negativa) advém de uma privação percepcional, entendida estritamente como uma carência ao nível da posse ou do exercício de um dos órgãos sensoriais ${ }^{18}$. E a premissa fundamental da respectiva demonstração é a de que todo o conhecimento depende em última instância da percepção ${ }^{19}$.

O raciocínio seguido parece ser o seguinte:

(1) todo o conhecimento procede ou por demonstração ou por indução;

(2) a demonstração lida com universais;

(3) os universais só podem ser atingidos por indução;

(4) toda a indução depende da percepção;

(5) logo, todo o conhecimento depende directamente (a indução) ou indirectamente (a demonstração) da percepção;

(6) logo, uma privação ao nível da percepção acarreta uma privação ao nível do conhecimento;

(7) logo, a ignorância negativa (= privação de conhecimento) advém de uma privação percepcional, na acepção anteriormente indicada.

As duas últimas consequências só são relevantes, nestes termos, no domínio estrito do problema que Aristóteles discute nesta secção dos Segundos Analíticos, isto é, o problema da ignorância e, em particular, da ignorância "negativa".

are called abstractions and the affections and the qualities of sensible things, are in the sensible forms' and hence cannot be considered apart from perception". (Aristotle's Posterior Analytics, p. 168).

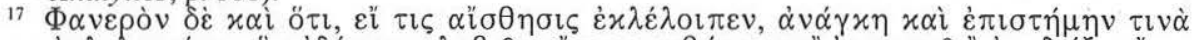

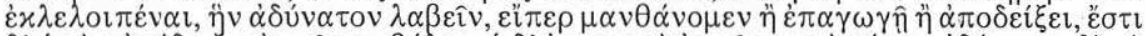

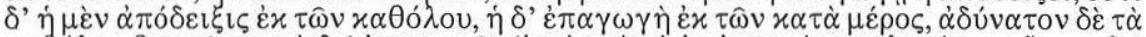

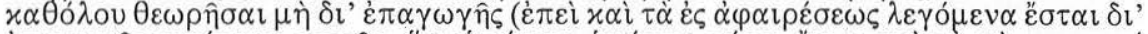

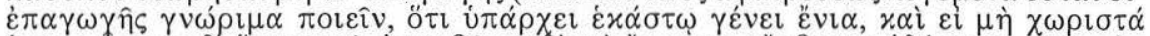

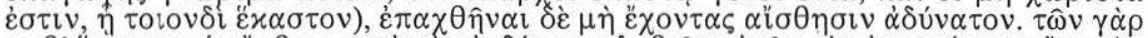

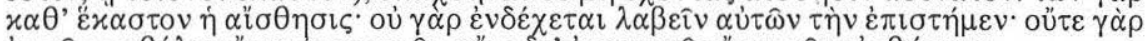

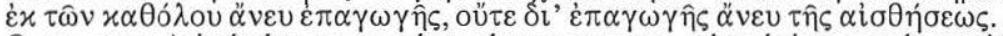

$\mathrm{O}$ que, para Aristóteles, parece desembocar na regra salomónica: a cada sentido que falta

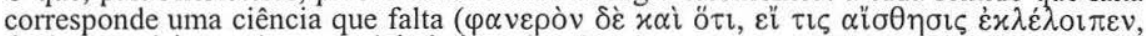

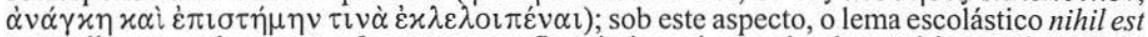
in intellectu quod non prius fuerit in sensu fica ainda muito aquém do empirismo aristotélico. É evidente que a tese aqui assumida supõe a teoria dos sensíveis próprios, cuja apreensão só é possível na condição de haver o sentido correspondente (De an. II 6, 418a11-16, cf. Insomn. I, 458b4-6; e detalhadamente De an. II 7-11, Sens. 3-5). Esta mesma questão é evocada por Aristóteles em Metaph. A 9, 993a7-8: não é possivel percepcionar os objectos de um determinado sentido sem possuir esse sentido.

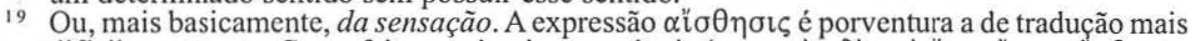

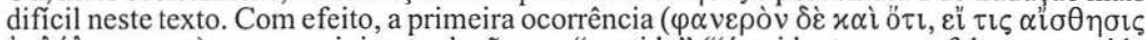
$\dot{\varepsilon} x \lambda \dot{\varepsilon} \lambda$ ot $\pi \varepsilon v$...) parece exigir a tradução por "sentido" ("é evidente que se falta um sentido ..."), uma vez que o pronome indefinido que a acompanha, seja ele interpretado como artigo ou como pronome, não tolera alternativas como "sensação" ou "percepção" (o que poderia significar, neste contexto, dizer que falta uma sensação ou uma percepção, ou certa sensação, ou alguma percepção? Daí o intolerável barbarismo da solução BARNES: "it is clear too that if some perception is wanting ..."). Ora esta primeira decisão condiciona a tradução de todas as ocorrências posteriores do termo, que a partir daí vertemos por "sensação", para não afastar da família lexical de "sentido". Na realidade, o que está em causa para Aristóteles neste capítulo é mesmo as consequências que decorrem da falta de um sentido e não o problema geral da ausência de dados sensoriais ou o problema ainda mais geral da dependência do 
As premissas de que parte (1-4) e a primeira consequência que retira (5) são, pelo contrário, de enorme importância para a compreensão da teoria aristotélica da ciência.

Todos os comentadores estarão de acordo em que Aristóteles argumenta aqui em favor de aquilo a que, de modo adequadamente muito vago e genérico, BARNES apelida de some sort of empiricist thesis ${ }^{20}$. O problema reside em caracterizar com rigor que espécie de empirismo é que Aristóteles exactamente aqui preconiza. assume.

Para o decidir, devemos começar por explicitar os supostos que o raciocínio

Desde logo, dois supostos colaterais são:

(3a) a demonstração depende da indução para a constituição da sua matéria (as premissas e, em última instância, os termos);

(4a) a matéria da demonstração (premissas e termos) é ultimamente haurida na percepção, ou, em geral, na experiência.

Ora, se as prolongarmos paralelamente à preocupação do texto e abstraindo dela, obtemos como conclusão fundamental de 1, 2, 3-3a, 4-4a e 5 que

(5a) todo o conhecimento começa com a experiência.

Todavia, daqui não se infere (i) o tipo de experiência que é exigida por esta tese nem (ii) que todo o conhecimento provém da experiência.

Não se infere que todo o conhecimento provém da experiência, porque a demonstração só depende da indução para a constituição da sua matéria e é só também no que toca à sua matéria que se funda ultimamente na percepção. Toda a teoria do silogismo e, em particular, do silogismo demonstrativo é, com efeito, em rigorosa oposição a todo o empirismo estreito, um momento de emancipação em relação à percepção.

Mas também não se infere o tipo de experiência que é exigida por esta tese, porque não se infere desde logo o tipo de indução que Aristóteles aqui preconiza. Ora é da decisão desta questão, para a qual o presente texto não dá elementos, que depende a caracterização da espécie de "empirismo" que Aristóteles propõe.

Um início de resposta a esta questão pode ser contudo entrevisto se encararmos em toda a sua amplitude o sentido e as consequências da ignorância negativa, que Aristóteles aborda nestes textos de uma forma extremamente circunscrita.

É que, na verdade, outros depoimentos de Aristóteles nos Segundos Analíticos permitem concluir que, se a encararmos desse modo amplo, todo o conhecimento humano pode ser visto como uma espécie de ignorância e como uma espécie de ignorância negativa, na acepção técnica deste capítulo, isto é, como uma ignorância derivada de uma privação sensorial. Ora este é que é evidentemente o ponto fundamental - e aquele no qual reside simultaneamente a chave para começar a caracterizar com mais precisão os contornos do "empirismo" aristotélico.

Com efeito, num extenso desenvolvimento dedicado à relação entre a percepção e o conhecimento do universal, Aristóteles retoma, por uma única vez em todo o tratado, o tema da privação sensorial, em termos todavia diferentes (ou justamente mais amplos) daqueles com que o encontrámos aqui trabalhado.

Depois de excluir que o conhecimento científico possa proceder por simples percepção, uma vez que os universais não podem ser percepcionados, enquanto que todo o conhecimento científico, em sentido rigoroso, isto é, toda a ciência demonstrativa, é necessariamente do universal, na medida em que é ele que "manifesta a causa" (ő $\tau \imath$

conhecimento em relação à percepção. Mas, em virtude da extraordinária bateria conceptual e teórica que convoca para situar o problema, torna-se perfeitamente legítimo avaliá-la de per $s i$, libertando a doutrina expendida da sua imediata circunstância argumentativa, que é aqui claramente de somenos. 


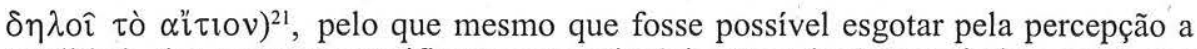
totalidade dos casos que verificam certo princípio não saberíamos ainda a causa que justamente os reúne sob esse princípio e portanto não teríamos obtido ainda o próprio princípio ${ }^{22}$, Aristóteles introduz esta restrição curiosa ${ }^{23}$ :

Há, no entanto, certos problemas que se reconduzem a um falha sensorial [ $\tilde{\varepsilon} \sigma \tau \imath$

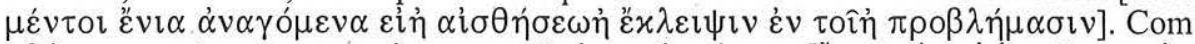

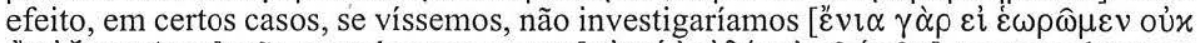

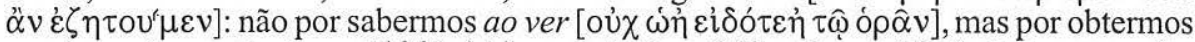

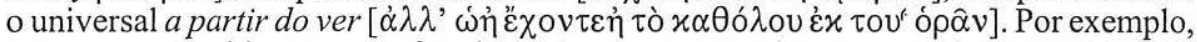
se víssemos o vidro a ser perfurado e a luz a atravessá-lo, tornar-se-ia manifesto tam-

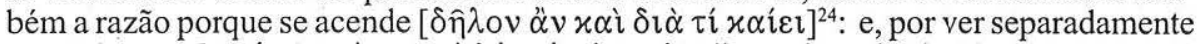
em cada caso [ $\tau \hat{\omega}$ ó $\rho \hat{\alpha} \nu \mu \dot{\varepsilon} v \chi \omega \rho \dot{\imath} \eta \dot{\varepsilon} \varphi^{\prime} \dot{\varepsilon} x \alpha \dot{\alpha} \sigma \tau \eta \hat{\eta}$ ], discernir-se-ia simultaneamente que

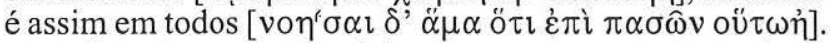

Ora não se trata aqui de uma mera concessão conjuntural, porque em outro texto vemos Aristóteles reeditar exactamente a mesma lição ${ }^{25}$ :

Mas que a investigação é do termo médio é o que se torna manifesto nos casos em que

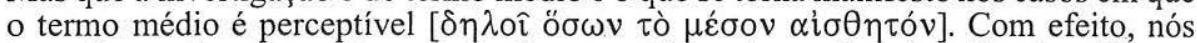

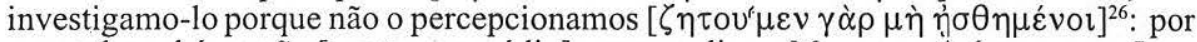
exemplo se há ou não [um termo médio] para o eclipse. Mas, se estivéssemos na Lua, não investigaríamos nem se há nem por que é que há: pois ambas as coisas seriam

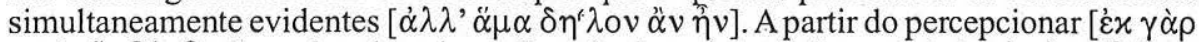

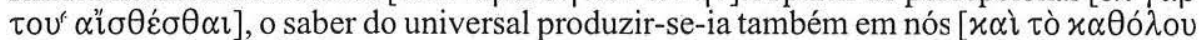
$\dot{\varepsilon} \gamma \varepsilon \dot{\varepsilon} v \varepsilon \tau 0 \ddot{\alpha} v \dot{\eta} \mu \hat{\imath} v \varepsilon \dot{i} \delta \varepsilon \dot{\varepsilon} \alpha_{l}$ ]: pois a percepção mostraria que [a Terra] se interpõe nesse momento (na medida em que é claro que [a Lua] se eclipsa); e através disto o universal

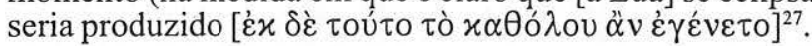

21 APo. I 31, 88a5-6.

22 Cf. APO. I 31, 87b28-88a11.

23 APO. I 31, 88a11-17.

24 Para Filipono (In APo. 311.16 Wallies; seguido por Tricot, Organon. IV: Les secondes

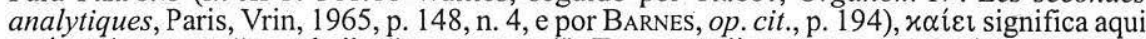

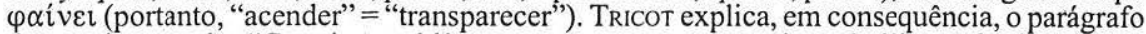
do seguinte modo: "Certains problèmes ne se posent qu'en raison de l'imperfection de nos sens. Le problème de la transparence du verre, par exemple, serait vite résolu, si nous pouvions voir la lumière et les pores du verre". Mas Ross (Aristotle's Prior and Posterior Analytics, p. 599) remete o exemplo para a explicação da inflamação do vidro dada por GóRGIAS (DK5 = TEOFRASTO, De igne 73). A admitir-se a primeira solução, o problema (de novo mencionado em APo. II 11, 94b28-31) é explicado pelo autor dos Problemata em XI 58, 905a35-b23 (e cf. XXV 9, 939a10-15). APo. II 2, 90a24-30.

26 É a leitura de Eustrato (In APo. 29, 24-27 Hayduck), adoptada também por Tricot, em vez da habitual permuta das orações: "se não o percepcionámos, investigamo-lo" (assim Ross e BARNES).

27 Este último texto é polémico, porque parece dizer exactamente o contrário do que um trecho que antecede o primeiro que acompanhámos. Em APo. I 31, 87b39-88a5, diz com efeito Aristóteles: "É por isso que, se estivéssemos na Lua e víssemos a Terra a interpor-se, não

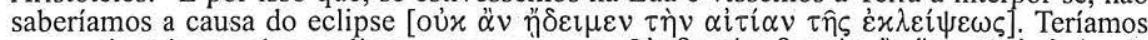

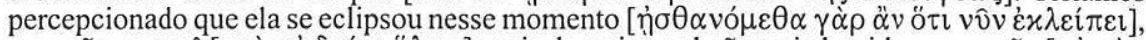
mas não porquê [ $x \alpha i$ oủ $\delta \imath o ́ \tau \iota ~ o ̈ \lambda \omega \varsigma]$; pois do universal não teria havido percepção [ou่ $\gamma \dot{\alpha} \rho$

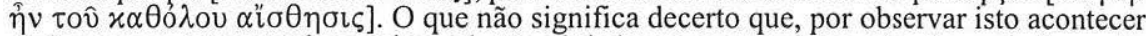
muitas vezes, procurando o universal, não obtivéssemos uma demonstração; pois é a partir

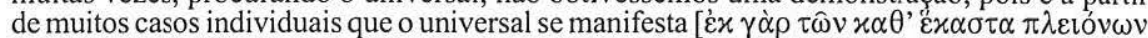

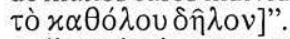

A divergência entre as duas passagens é contudo mais aparente do que real; e é fácil reconciliá-las se justamente se admitir a sintonia doutrinária dos trechos citados no corpo do texto. Pois, com esta presunção, a solução encontra-se na própria cláusula fundamental do primeiro: 
O que é que está verdadeiramente em causa nestes dois textos?

À primeira vista, encontramo-nos perante uma simples ocorrência daquilo a que Ross chamou a "indução generalizante" conclui-se, para todos os casos, que é verdade que $P$. E, de facto, o exemplo de Aristóteles na parte final do primeiro texto parece ir claramente nesta direcção: "se vissemos o vidro a ser perfurado e a luz a atravessá-lo, tornar-se-ia manifesto também a razão porque se acende: e, por ver separadamente em cada caso, discernir-se-ia simultaneamente que é assim em todos".

Todavia, se há realmente uniformidade de lição entre os dois textos, esta doutrina não pode ser admitida sem mais como a assumida pelo primeiro. Pois o segundo enfatiza sem ambiguidades que, em certos casos (nomeadamente na hipótese de assistirmos in loco a um eclipse da Lua) "através do percepcionar, o saber do universal produzir-se-ia também em nós: pois a percepção mostraria que [a Terra] se interpõe nesse momento (...); e através disto o universal seria produzido". Ora neste segundo texto não há qualquer menção à necessidade de uma multiplicidade de experiências coincidentes, senão que, pelo contrário, todo o texto é construído para ilustrar uma situação em que "o termo médio é perceptível" e em que portanto a própria percepção de um caso, manifestando por si mesma a causa e deste modo libertando ao mesmo tempo $(\ddot{\alpha} \mu \alpha)$ o princípio universal, torna escusada e supérflua qualquer investigação subsequente.

Mas há uma outra razão, bem mais importante, para não reduzirmos todo o sentido do primeiro texto à indução generalizante. É que, se o fizéssemos, perderíamos de vista

"com efeito, em certos casos, se víssemos, não investigaríamos: não por sabermos ao ver, mas por obtermos o universal a partir do ver". Ou seja: em caso algum a tese aristotélica é a de que a própria percepção constitui por si só o conhecimento do universal; o que ela declara é que, em certas circunstâncias, o universal é imediatamente libertado pela percepção e que portanto, nessas circunstâncias, o conhecimento do universal é simultaneamente produzido

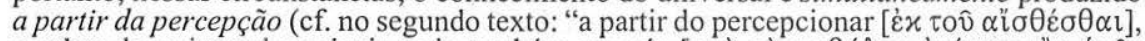

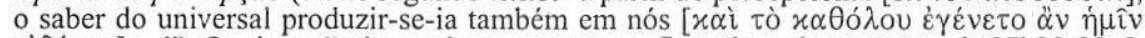

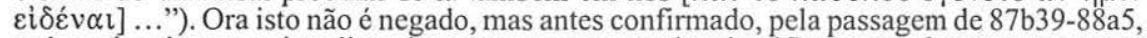
a despeito de o seu imediato interesse argumentativo justificar uma forma que parece superficialmente contradizer $A P O$. II 2.

Para o comprovar, libertemo-lo de qualquer ambiguidade, explicitando tudo o que ele dá por suposto. Diz então Aristóteles: "É por isso que, se estivéssemos na Lua e víssemos a Terra a interpor-se, não saberíamos [pela percepção] a causa do eclipse. Teríamos percepcionado que ela se eclipsou nesse momento, mas não [teríamos percepcionado] porquê; pois do universal não teria havido percepção". Claramente, a doutrina é agora homogénea nos três casos, embora o objectivo do último seja diferente dos dois outros: naquele, trata-se de sublinhar que a percepção nunca é por si só um conhecimento do universal; nestes, trata-se de ressalvar que, muito embora assim seja, a percepção pode por vezes ser suficiente para que a partir dela se produza imediatamente um tal conhecimento. Só assim se compreende aliás que Aristóteles possa fazer suceder sem contradição o primeiro trecho no corpo do texto à passagem introduzida nesta nota.

Para a distinguir da "indução indutiva" e da "indução perfeita" (ou "silogismo indutivo"): cf. Aristotle's Prior and Posterior Analytics, pp. 48-50. A expressão "indução indutiva”, que Ross remete para o uso comum ("this is in fact what modern logicians call intuitive induction"), foi de facto cunhada pelo lógico britânico W. E. Johnson (cf. Logic. Part II: Demonstrative Inference, Deductive and Inductive, Cambridge, Cambridge University Press, 1922, reed. New York, Dover Publications, 1964, chs. VIII-IX); a expressão "silogismo indutivo" pertence

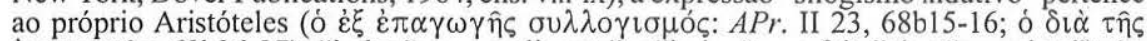
$\dot{\varepsilon} \pi \alpha \gamma \omega \gamma \hat{\eta}$ : $_{\text {: }}$ 68b36-37); "indução generalizante" e "indução perfeita" (ou "completa") são expressões imediatamente construídas a partir do procedimento próprio de cada um dos respectivos tipos de indução: a primeira generaliza a partir de um número dado de casos, a segunda tem de esgotar a totalidade desses casos $(\delta \imath \dot{\alpha} \pi \dot{\alpha} \nu \tau \omega \nu)$. Em muitos aspectos, a análise de Ross permanece inexcedível; ela é, em todo o caso, um marco incontornável no tratamento desta questão: veja-se todo o desenvolvimento que lhe dedica a pp. 47-51, bem como os comentários pontuais às diversas ocorrências do conceito. 
o ponto fundamental desse texto. Pois o que faz a sua especificidade não é a requisição de uma multiplicidade de experiências para a extracção de um universal ${ }^{29}$, mas, rigorosamente ao contrário, a ideia de que tal multiplicidade de experiências só é requerida porque a nossa percepção é constitutivamente deficitária.

Com efeito, o ponto fundamental do texto é que, se a visão fosse suficientemente penetrante $^{30}$, o universal compareceria imediatamente perante ela. Ora é justamente porque a visão não é suficientemente penetrante (dir-se-ia: porque não é por si mesma

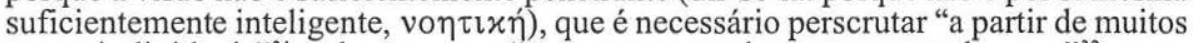
casos individuais" 31 e de começar "por ver separadamente em cada caso" 32 , para finalmente poder "discernir simultaneamente que é assim em todos"33. E é precisamente esta regra que o segundo texto consagra, ao aduzir um caso em que a nossa visão seria suficiente para apreender imediatamente o universal a partir de uma única instância: "Se estivéssemos na Lua, não investigaríamos nem se há nem por que é que há: pois ambas as coisas seriam simultaneamente evidentes. A partir do percepcionar, o saber do universal produzir-se-ia também em nós: pois a percepção mostraria que [a Terra] se interpõe nesse momento (na medida em que é claro que [a Lua] se eclipsa); e através disto o universal seria produzido".

Todavia, se é possível discernir que é assim em todos os casos, perscrutando apenas muitos casos (não todos) e mesmo perscrutando apenas um (se a visão fosse suficientemente penetrante), é porque evidentemente aquilo que nos permite passar de alguns (muitos, poucos ou um) a todos, isto é, aquilo que nos permite passar do particular ao universal, não é a multiplicação de casos (um, em abstracto, bastaria), nem muito menos a abusiva passagem de muitos a todos, mas a capacidade de discernir $o$ que se diz de todos, isto é, o universal, em alguns (muitos, poucos ou um) daqueles de que isso se diz.

A regra que aconselha a perscrutar muitos casos não radica portanto em qualquer tipo de ilusão acerca do valor inferencial ou probatório da multiplicidade das "experiências": pelo contrário, para Aristóteles é claro que perscrutar muitos casos ou poucos casos vale rigorosamente o mesmo quando se trata de concluir o que vale para todos. Tal regra não é senão uma vénia prudencial perante a intrínseca limitação das nossas capacidades perceptivas: a nossa visão não é suficientemente penetrante.

Mas em que reside uma tal limitação?

Reside, evidentemente, na insuficiente penetração da nossa sensibilidade, isto é, na sua incapacidade para por si mesma discernir o universal. A limitação da nossa sensibilidade é portanto uma limitação noética, a saber, uma incapacidade para inteligir ou discernir o que perante ela se manifesta; o mesmo é dizer que a limitação da nossa sensibilidade é um defeito de inteligência, defeito que não é no entanto dela, por não ver as coisas inteligentemente, mas nossa (quer dizer, da nossa própria natureza, enquanto dotados de semelhante sensibilidade), por não vermos as coisas com a inteligência ${ }^{34}$.

29 Procedimento aliás muito discutível de o obter (veja-se a propósito as judiciosas observações de Ross sobre $\mathrm{a}$ indução generalizante) e que não resistiria às críticas humeanas contra o valor inferencial da indução. Poder-se-ia ver, num estudo inteiramente devotado a esta noção, que não é nunca este procedimento que Aristóteles concebe sob o título de $\dot{\varepsilon} \pi \alpha \gamma \omega \gamma \eta \dot{\text {. }}$

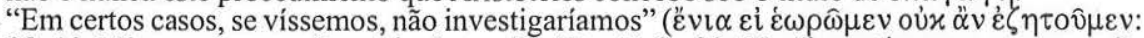
88a12-13); ou, na versão mais forte de $A P o$. II 2, 90a25, "investigamos, porque não

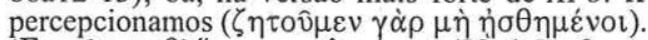

${ }_{31} \mathrm{E} \varkappa \tau \hat{\omega} \nu \varkappa \alpha \theta^{\prime}$ ' $\check{x} \alpha \sigma \tau \alpha \pi \lambda \varepsilon \operatorname{lov\omega \nu }$ (88a4-5; cf. supra, n. 27, para a citação completa).

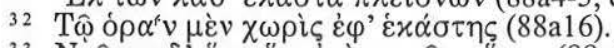

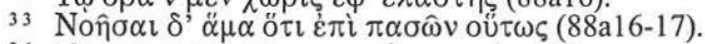

34 No presente texto, assumiremos duas teses sem as desenvolver: $\left.1 .^{a}\right)$ que o vov̂ é, em Aristóteles, fundamentalmente uma capacidade discriminatória, cuja melhor tradução seria dada pelo português "discernimento"; 2. ${ }^{\text {a) }}$ que o vov̂s está em Aristóteles articulado com a sensibilidade e intervém logo ao nível perceptivo. Na impossibilidade de demonstrar cabalmente aqui estas duas teses, resta-nos remeter, sem comentário, para o próprio texto aristotélico: 
Em tudo isto está contudo implícito um suposto decisivo: é que o universal manifesta-se $e^{35}$. Pois só na presunção de que o universal de algum modo se mostra é possível esperar que a percepção das coisas (de muitas, de poucas ou de uma) possa facultar o seu discernimento. Nesta medida, dizer que, se a visão fosse suficientemente penetrante, o universal compareceria imediatamente perante ela não significa senão dizer que, nesse caso, o universal transpareceria imediatamente nas coisas singulares ${ }^{36}$.

Ora é esta presunção de que o universal se manifesta e se dá à percepção e de que uma inteligência treinada ou excepcionalmente intuitiva é capaz de o discernir imediatamente nas coisas singulares ${ }^{37}$ que justifica o papel da experiência na doutrina aristotélica da ciência. É que, se é certo que para passar do particular ao universal tanto dá, consoante as capacidades intelectivas do sujeito, partir de muitos, de poucos ou de um, o que é igualmente certo é que tem de haver algum. Ora é nisto que está todo o proverbial empirismo de Aristóteles: o discernimento dos universais não opera sozinho, mas carece de aquilo em que esses universais podem ser discernidos, a saber, os singulares; o voúç não trabalha sozinho, mas precisa que um objecto lhe seja dado, o qual só pode provir da percepção ${ }^{38}$.

Dizer, portanto, como no início deste parágrafo, que todo o conhecimento começa com a experiência, na medida em que a ciência carece dos universais como sua matéria e estes só podem ser atingidos por indução e, logo, por percepção, não significa senão dizer que só pode haver ciência se houver uma certa faculdade que lhe entregue os

veja-se, para a primeira, De an. III 3, 427a19-21; III 9, 432a15-17; MA 6, 700b15-23; e, para a segunda, novamente $M A 6,700 \mathrm{bl5}-23$, e $E N$ VI 12,1143a35-b5, b9-11.

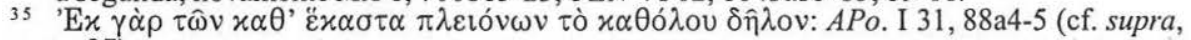
n. 27).

36 Este o inegável platonismo da teoria aristotélica da ciência, que aliás o próprio Aristóteles implicitamente reconhece nas passagens em que, com muita sagacidade, comenta a doutrina platónica da reminiscência (cf. $A P r$. II 21, 67a8-26, e $A P o$. I 1, 71a17-b8).

37 Veja-se a este propósito a expressiva definição de acúmen (ou, na sugestiva tradução de

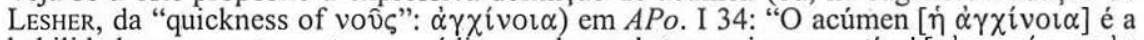

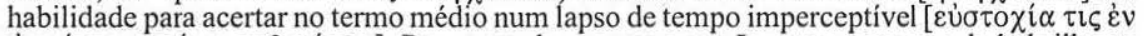

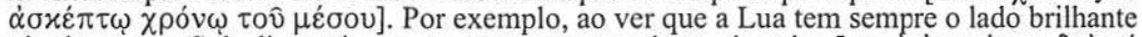

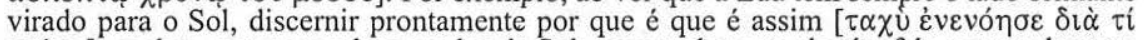

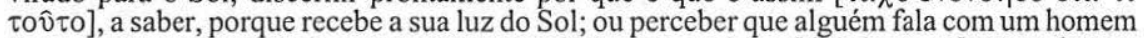
rico para lhe pedir dinheiro emprestado; ou ainda por que é que [dois homens] são amigos, a saber, porque são inimigos de um terceiro. Ao ver os extremos, conheceu-se todos os termos

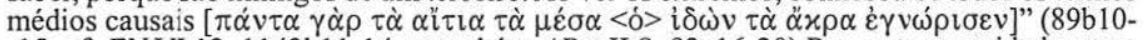
-15; cf. EN VI 12, 1143 b11-14, e também APo. II 8, 93a16-20) Para esta capacidade como resultado de um habitus intelectual em tudo semelhante ao habitus da moralidade, veja-se Top. VIII 14, 163b9-16 (e cf. L. A. KosmAN, "Understanding, Explanation and Insight in the Posterior Analytics", Exegesis and Argument, Studies in Greek Philosophy presented to Gregory Vlastos, ed. E. N. Lee, A. P. D. Mourelatos, R. M. Rorty, Assen, Van Gorcum, 1973, pp. 374-392; D. W. Hamlyn, "Aristotelian Epagoge", Phronesis, 21, 1976, pp. 167-187; M. Burnyeat, "Aristotle on Learning to be Good", Essays on Aristotle's Ethics, ed. A. O. Rorty, Berkeley, University of California Press, 1980, pp. 69-92; e o excelente comentário de R. SMITH a esta passagem em Topics Books I and VIII, Oxford, Clarendon Press, 1994, pp. 154-155).

38 Até nisto, no entanto, não está Aristóteles muito longe de seu mestre Platão: se lembrarmos o que este afirma no Fédon acerca das condições da reminiscência (cf. 74a-75d). O antiplatonismo de Aristóteles, dito de outro modo, não está na teoria da ciência, mas sim na ontologia. Para ambos, o universal transparece no singular, só que de modos irredutivelmente diferentes. Para Platão, o "universal" transparece no "singular", porque aquele é tudo o que este verdadeiramente é; para Aristóteles, o universal transparece no singular, porque o que este é, sendo individual, dá-se sempre num horizonte de universalidade. Nesta medida, para Platão, o "singular" não é mais do que um mero cruzamento de "universais"; para Aristóteles, é um irredutivel este, aqui e agora (APO. I 31, 87b28-33). Assim, embora para ambos o universal transpareça no singular, só Aristóteles os pensa como universal e singular. $\mathrm{O}$ indivíduo é pois o nome da diferença entre Platão e Aristóteles. 
universais que discerniu na experiência e, portanto, que a ciência repousa no voú como no seu princípio ${ }^{39}$; mas significa também que o próprio voús só é posto em exercício em presença de determinada experiência que lhe tem de ter sido previamente dada $^{40}$.

O ponto de charneira que o primeiro grupo de textos citado neste parágrafo havia omitido e por cuja omissão nenhuma resposta acerca da natureza da experiência requerida pela teoria aristotélica da ciência podia ser decidida é portanto o voúc, quer enquanto capacidade de discernimento do universal nos singulares, quer, neste sentido, enquanto

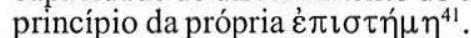

Ora daqui resulta uma imediata ilação no que toca à compreensão do segundo grupo de textos estudados. É que, ao contrário do que inicialmente se diria, não é perante a indução generalizante que no primeiro texto nos encontramos, mas (como o segundo torna manifesto) perante a indução "intuitiva", isto é, a indução que não opera por generalização e portanto em dependência de um número significativo de casos, mas justamente por discernimento noético do universal a partir de qualquer número de casos; mais do que isso, que não é a indução pensada nos termos do segundo texto ${ }^{42}$ que carece de ser reinterpretada nos termos do primeiro ${ }^{43}$, nem em geral a indução "intuitiva" como um modo (ou antes, como um lapso) da indução "generalizante", mas, pelo contrário, é esta que constitui uma expressão particular daquela, na medida exclusiva em que a limitação da nossa sensibilidade implica a multiplicação dos casos com vista à evidenciação do universal (mas não a sua generalização, com vista a uma putativa inferência).

Esta a chave para compreender o verdadeiro lugar da privação sensorial, em sentido amplo, na reflexão aristotélica sobre o conhecimento e para desse modo aceder a uma panorâmica geral da relação entre ignorância e saber em Aristóteles.

É que, neste âmbito, a verdadeira privação sensorial é aquela que advém de possuirmos uma sensibilidade que não é em si mesma inteligente ou intelectiva, isto é, que não é capaz de discernir imediatamente o universal. A verdadeira privação sensorial é pois a que reside no facto de não termos (em sentido estrito) uma intuição intelectual, quer dizer, uma faculdade sensível que seja enquanto tal capaz de inteligir.

Ora é porque isto é assim que temos de investigar: pois, se todos os casos fossem como aqueles que os dois textos descrevem, "se víssemos, não investigaríamos". Todo o nosso conhecimento repousa pois numa falência constitutiva dos nossos sentidos; e todo ele não é portanto senão uma espécie de ignorância fundamental - se, evidentemente, por "saber" se entender a requisição hiperbólica de um ver sensível que seja ao mesmo tempo intelectivo.

O que todavia caracteriza o pensamento aristotélico a este respeito é justamente $a$ recusa de uma tal requisição, que é como quem diz, é justamente a conformação com a natureza peculiar da nossa capacidade cognitiva. E por isso, a despeito dessa ignorância, quer dizer, a despeito da deficiência intrínseca da nossa percepção, o conhecimento que se constrói por investigação e toma a forma final de uma demonstração explicativa merece sem reservas, e por antonomásia, o nome de "saber". O conhecimento da percepção, pelo contrário, limitado como está a fornecer aquilo em que o universal é discernido, mas jamais a discernir ele próprio o universal, não é um saber, senão um caminho para o saber.

39 Tese aliás repetidamente afirmada em diversas passagens: veja-se $A P o$. I 3, 72b23-25; I 23, 84b37-85al; I 33, 88b36; II 19, 100b14-15.

40 Cf. de novo 88a14-17: "Se víssemos o vidro a ser perfurado e a luz a atravessá-lo, tornar-se-ia manifesto também a razão porque se acende: $e$, por ver separadamente em cada caso, discernir-se-ia [vô̂ $\alpha \mathrm{l}]$ simultaneamente que é assim em todos".

41 Cf. APo. I 3, 72b18-25; I 23, 84b31-85a 1; I 33, 88b30-89a4; II 19, 100b5-17; ver ainda APo. I 24, 86a22-30.

42 Cf. $A P O$. II 2, 90a26-30.

43 Cf. $A P O$. I $31,88 \mathrm{a} 2-5$. 
Contudo, esse caminho, que parte da ignorância em que a nossa natureza está primitivamente instalada, é também já simultaneamente um caminho para a transcenção dessa ignorância e, mais do que isso, o próprio caminho em que tal transcenção se realiza. E nesta medida, no jogo de saber e ignorância em que começa por se decidir o sentido e a orientação da teoria aristotélica da ciência, não é o saber que se revela como uma ignorância fundamental: é o próprio lugar onde a ignorância parece residir e é a própria fonte de onde ela aparentemente dimana que se virá a revelar como o lugar e a fonte do único saber verdadeiro.

Mas isso seria já tema para um outro escrito. 
